\title{
Keeping the Vermin Out: Perceived Disease Threat and Ideological Orientations as Predictors of Exclusionary Immigration Attitudes
}

\author{
EVA G. T. GREEN ${ }^{1 *}$, FRANCISKA KRINGS ${ }^{1}$, CHRISTIAN STAERKLÉ $^{1}$, \\ ADRIAN BANGERTER ${ }^{2}$, ALAIN CLÉMENCE ${ }^{1}$, \\ PASCAL WAGNER-EGGER ${ }^{3}$ and THIERRY BORNAND ${ }^{1}$ \\ ${ }^{1}$ University of Lausanne, Lausanne, Switzerland \\ ${ }^{2}$ University of Neuchâtel, Neuchâtel, Switzerland \\ ${ }^{3}$ University of Fribourg, Fribourg, Switzerland
}

\begin{abstract}
Integrating evolutionary and social representations theories, the current study examines the relationship between perceived disease threat and exclusionary immigration attitudes in the context of a potential avian influenza pandemic. This large-scale disease provides a realistic context for investigating the link between disease threat and immigration attitudes. The main aim of this cross-sectional study $(N=412)$ was to explore mechanisms through which perceived chronic and contextual disease threats operate on immigration attitudes. Structural equation models show that the relationship between chronic disease threat (germ aversion) and exclusionary immigration attitudes (assimilationist immigration criteria, health-based immigration criteria and desire to reduce the proportion of foreigners) was mediated by ideological and normative beliefs (social dominance orientation, belief in a dangerous world), but not by contextual disease threat (appraisal of avian influenza pandemic threat). Contextual disease threat only predicted support for health-based immigration criteria. The conditions under which real-life disease threats influence intergroup attitudes are scrutinized. Convergence and dissimilarity of evolutionary and social representational approaches in accounting for the link between disease threat and immigration attitudes are discussed. Copyright (C) 2010 John Wiley \& Sons, Ltd.
\end{abstract}

Key words: disease threat; social representations theory; evolutionary psychology; immigration attitudes; SDO; BDW

\section{INTRODUCTION}

Throughout history foreigners have been associated with disease. Disease-carrying animals, such as rats, lice or cockroaches have been invoked to depict foreign outgroups

* Correspondence to: Eva G. T. Green, Faculty of Social and Political Sciences, University of Lausanne, Vidy, CH1015 Lausanne, Switzerland. E-mail: eva.green@unil.ch 
(Bar-Tal, 1990; Savage, 2007; Suedfeld \& Schaller, 2002). Epidemics named after outgroups, such as the 15th century labels for syphilis as 'French pox' by the English, or as 'Chinese disease' by the Japanese (Joffe, 1999; Sontag, 1989), were commonplace. Immigration policies have been tainted by this perception of disease threat, illustrated by unwarranted medical inspections of incoming immigrants originating from regions suspected to harbour dangerous diseases (Markel \& Stern, 2002).

While a long tradition of research in social psychology has demonstrated the predictive impact of both realistic and symbolic threat on prejudice towards outgroups (e.g. Allport, 1954; Esses, Jackson, \& Armstrong, 1998; Riek, Mania, \& Gaertner, 2006; Sherif, 1967; Stephan \& Renfro, 2003), only recently has research also revealed the impact of disease threat on negative outgroup attitudes (e.g. Faulkner, Schaller, Park \& Duncan, 2004; Joffe, 1999; Navarette \& Fessler, 2006; Schaller, 2006), thereby providing a new motivational explanation for negative immigration attitudes. Yet, the mechanisms shaping the link between disease threat and prejudice still require clarification. How exactly does perceived disease threat translate into negative or hostile attitudes towards immigrants? In order to address this question, we carried out a survey study in the fall of 2005 when the increase of avian influenza cases first entered the media spotlight. Our main argument is that in order to understand how perceived disease threat affects prejudice, it is necessary to investigate the representations and ideological beliefs that are triggered by disease threat. To do so, we propose an integrative framework of perceived disease threat, which is based on an evolutionary perspective and social representations theory.

\section{DISEASE THREAT AND PREJUDICE}

An evolutionary approach linking disease avoidance and prejudice assumes that negative immigration attitudes are an adaptive strategy, resulting from functional psychological processes that evolved in ancestral environments to motivate avoidance of individuals who pose a potential threat in terms of transmission of pathogens and parasites (Faulkner et al., 2004; Kurzban \& Leary, 2001; Schaller, 2006). In addition to sophisticated physiological mechanisms (e.g. the immune system), arousal of aversive cognitive and emotional responses evolved in response to perceiving disease-carrying parasites and their hosts. This line of thinking suggests that current-day prejudice partially results from the overactivation of such mechanisms, which lead to the avoidance of contact with people who are potential disease carriers. Members of foreign groups are more likely seen as engaging in unfamiliar practices that violate ingroup customs (e.g. hygiene in food preparation) and that thus may increase transmission of pathogens. Risk of disease transmission is a potential cost of interacting with foreigners, whereas opportunities to establish alliances and to learn from such interactions are benefits (Schaller \& Murray, 2008). Xenophobic responses emerge when the potential costs outweigh the potential benefits. Indeed, Faulkner et al. (2004) experimentally demonstrated that aroused perceptions of disease vulnerability triggered xenophobic responses. However, because of the high potential costs of erroneously judging that a disease-carrying individual is actually healthy, the disease avoidance mechanism is biased towards classifying individuals as diseased (Haselton \& Nettle, 2006; Kurzban \& Leary, 2001). This implies an evolved capacity to learn that certain stimuli indicate danger and disease (Öhman \& Mineka, 2001).

Disease-avoidant psychological responses nevertheless vary across persons. Especially when people feel vulnerable to infection, they not only stigmatize sick people, but also 
individuals who appear to carry a risk of parasite transmission on the basis of a superficial cue (Schaller, 2006), and subjective foreignness can thereby become a heuristic cue for disease. This is why perceived vulnerability to disease relates to negative attitudes towards immigration (Faulkner et al., 2004), but also to negative attitudes towards obese and disabled persons (Park, Faulkner, \& Schaller, 2003; Park, Schaller, \& Crandall, 2007). Evolved pathogen-detection mechanisms thus trigger prejudice also towards individuals with non-normative morphology. Extending the findings from outgroup avoidance to ingroup attraction (see Brewer, 1999), Navarette and Fessler (2006) argued that disease threat is also an adaptive challenge for coalitional ties within groups.

Emphasizing the disease threat-prejudice link at a cultural level, the disease-avoidance approach has been applied to investigate cross-cultural differences of ideological beliefs. Thornhill, Fincher, and Aran (2009) showed prevalence of conservatism, autocracy and gender inequality in countries with high historic and current disease risk. In a regional-level level analysis, Schaller and Murray (2008), in turn, found that personality traits such as extraversion and openness to experience were associated with lower levels of disease prevalence and argued that multiple social interactions and curiosity can increase exposure to disease and are thus not adaptive. These findings lend support to the link between disease threat and prejudice to the extent that conservatism, autocracy and lack of openness are ideological beliefs or traits that have been associated with prejudice.

A social representational approach complements the evolutionary view by showing how fears and anxieties are collectively shared and culturally transmitted (Joffe, 1999, 2003). This approach draws on cultural theory (e.g. Douglas, 1992) to investigate the processes through which shared beliefs and explanations of emerging new epidemics such as avian influenza, AIDS or Ebola are socially constructed and transmitted. Shared beliefs constitute a collective means of coping with societal threat (Jodelet, 1991; Sanchez-Mazas \& Licata, 2008; Wagner, Kronberger, \& Seifert, 2002). The symbolic environment offers vivid images and vibrant accounts of disease threats, which become reference marks used in the elaboration of everyday explanations of epidemics. Through mass media and in everyday interpersonal communication, people become aware of and develop an understanding about epidemics. They rely on such symbolic reference marks to spread lay knowledge on epidemics.

Research adopting a social representational approach has therefore primarily focused on collective sense making, expressed in shared belief systems. People are, for example, prone to associate diseases to supposedly inferior, dirty or unhealthy outgroups and their counternormative and deviant practices (often related to sex or hygiene). Such groups are typically viewed as representing the antithesis of the valued attributes of body control and moral decency (Joffe \& Staerklé, 2007). In a study on representations of Ebola in the British press and held by newspaper readers, Joffe and Haarhoff (2002) found that Ebola was associated with negative stereotypes of Africa and African practices. Joffe and Lee (2004), in turn, found that Hong Kong women attributed lack of hygiene to Mainland Chinese poultry producers to explain the 2001 avian influenza epidemic. The social representational view emphasizes the symbolic association between disease threats and outgroups, and thereby the preservation of the imagined 'purity' of the ingroup and the protection of its positive identity (Jodelet, 2005; Joffe, 1999; see also Nemeroff, 1995; Rozin, Haidt, \& McCauley, 2000). Hence, an appearance of a new disease such as avian influenza typically triggers the need to draw a line between the ingroup and threatening outgroups.

In sum, the evolutionary approach focuses on adaptive disease avoidance processes with ancestral origins, whereas the social representations approach highlights the symbolic, 
collective elaboration and transmission of contemporary belief systems as a reaction to disease. While the epistemological origins of the two approaches differ, they converge in arguing that heightened disease threat gives rise to negative attitudes towards foreign outgroups. These approaches thus provide complementary ingredients leading to an integrative model that involves ideological beliefs as psychological mechanisms underlying the link between disease threat and exclusionary immigration attitudes.

\section{DISEASE THREAT, IDEOLOGICAL BELIEFS AND EXCLUSIONARY IMMIGRATION ATTITUDES}

The model outlined in this paper suggests that vulnerability to disease heightens exclusionary immigration attitudes through ideological beliefs. To address the link between perceived disease threat and exclusionary immigration attitudes, chronic and contextual disease threats are distinguished and their effects on prejudice compared. Research based on an evolutionary perspective has shown that chronic fear of disease, in particular germ aversion, is a key driving force of xenophobic attitudes (Faulkner et al., 2004). Contextual disease threat, in turn, concerns temporarily heightened and highly mediatized fears about disease, which have also been shown to trigger xenophobic attitudes (e.g. Faulkner et al., 2004; Joffe \& Haarhoff, 2002). Moreover, the impact of disease threat has been shown to vary as a function of prejudice: Perceived avian influenza threat was related to outgroup avoidance only among prejudiced individuals (Krings et al., 2009). Both evolutionary and social representational approaches have demonstrated that such temporary fears (e.g. fear of avian influenza) amplify negative reactions towards social categories heuristically associated with the disease.

First, in order to account for the relationship between disease threat and exclusionary immigration attitudes, we suggest that chronic disease threat is likely to increase contextual disease threat. It seems plausible that individuals who are chronically afraid of contagious diseases will be particularly attentive to contextual disease cues, which subsequently trigger avoidance of foreigners. Chronic disease threat should thus increase the awareness and fear of an emerging epidemic (such as avian influenza) that is made salient through extensive mass media coverage and everyday discussions. Therefore, the relationship between chronic disease threat and exclusionary immigration attitudes should at least be partially mediated by the contextual appraisal of the specific disease threat.

Second, ideological belief systems that construct and maintain social hierarchies (Doise, 1990; see also Augoustinos, Walker, \& Donaghue, 2006; Jost \& Major, 2001) should also intervene in the relationship between chronic disease threat and exclusionary immigration attitudes. In line with a social representational approach, research has shown that threatening situations generate collective definitions of the threat that are used by group members both to cope with the threat and to take measures to protect themselves and their group. Authoritarianism research has for example demonstrated that in times of societal threat, endorsement of authoritarian beliefs increases (Doty, Peterson, \& Winter, 1991). Closer to our concern, disgust sensitivity feeds into ideological orientations (SDO and authoritarianism), which further increase negative intergroup attitudes (Hodson \& Costello, 2007). Relying on this general principle that disease threat activates shared representations to which individuals refer in uncertain and threatening times, we expect that disease threat promotes two types of ideological beliefs, namely the belief in a dangerous world (BDW) and social dominance orientation (SDO). 
Chronic disease threat should evoke representations inducing people to stay vigilant in face of the threat in order to avoid the disease. The belief in a dangerous world scale (BDW; Altemeyer, 1988) captures ideological beliefs, which emphasize the dangers of current-day society and the ensuing need for protection. When considered as a reaction to disease threat, the danger comes from disease carriers, which must be separated from safe healthy persons. Subsequently, those who believe that society is dangerous are more likely to express exclusionary immigration attitudes than those who perceive a safer society (Duckitt, 2001). Thus, we conceive of chronic disease threat as an antecedent of BDW, such that BDW should at least partly mediate the relationship between chronic disease threat and exclusionary immigration attitudes.

Enhancing societal hierarchy is another strategy to deal with disease threat. Subordinate outgroups are more likely to be associated with disease and, correspondingly, dominant ingroups are more likely to be viewed as safe and healthy (see Joffe, 1999). Therefore, chronic disease threat should promote an ideology of social dominance (SDO; Sidanius \& Pratto, 1999) that expresses a desire for group-based dominance and opposition to social equality (Hodson \& Costello, 2007). This ideology is rooted in the notion that society is a competitive jungle (Duckitt, 2001) in which, in an evolutionary view, the healthy will have an adaptive advantage over the sick. The maintenance of control and hierarchy in society is therefore necessary to keep low status and potentially disease-carrying outgroups in their place. Thus, we expect that the link between chronic disease threat and exclusionary immigration attitudes should also be mediated by SDO (see also Guimond, Dambrun, Michinov, \& Duarte, 2003, on the mediating effects of SDO).

\section{CURRENT STUDY}

Since immigrants are potentially associated with disease contamination, it is important to inquire how an emerging infectious disease such as avian influenza shapes attitudes towards immigrants and immigration. Avian influenza is a contagious disease of animals caused by viruses that normally infect only birds. However, avian influenza viruses have previously crossed the species barrier to infect humans (World Health Organization WHO, 2009). According to the WHO, the risk of an avian influenza pandemic is currently increasing and is higher than at any time since 1968, when the last pandemic occurred. Human infections and deaths over the last years have increased the awareness of the risks posed by this disease to humans. The current study was carried out in fall 2005 in Switzerland when the outbreak of avian influenza was widely reported in Swiss and international media as a major public health threat. Attention was drawn to human cases, affected areas, probability of disease transmission from animals to humans, vaccines and pandemic preparedness of governments (e.g. The Economist, 2005; Osterholm, 2005). Media often sensationalized the risks by presenting worst-case scenarios in their avian flu coverage (Dudo, Dahlstrom, \& Brossard, 2007). In addition, US polls showed that perceptions of avian flu threat, such as concern of the spread of the disease, were highest at this early stage of the outbreak (Ho, Brossard, \& Scheufele, 2007). Therefore, avian influenza threat provided a realistic context (de Zwart et al., 2007) for studying the link between disease threat and exclusion of immigrants, and the belief systems that may explain this link. 
In this study, three indicators of exclusionary immigration attitudes were used. Each of them reflected in different ways the demarcation of national group boundaries and the exclusion of immigrants and foreigners from within these boundaries (Pehrson \& Green, in press). First, we measured the support for assimilationist entry criteria for immigrants (Green, 2007, 2009), which represents a protective and restrictive attitude which grants entry to Switzerland only to those who conform to a set of attributes defining 'appropriate' immigrants (e.g. educational qualifications, working skills or the readiness to adopt the way of life and values of the host culture). Since our study deals with a public health threat, we distinguished stances towards health status of immigrants from other criteria. Thus, the second indicator concerned restrictive health-related immigration attitudes, based on the idea that immigrants need to be in good health in order to be granted the right to enter the country. Since human-to-human transmission of avian influenza was highly unlikely at the time of our study, support for health-based entry criteria is irrational and indeed depicts prejudice. The third indicator concerned immigrants who are already present in the country, tapping the desire to reduce the proportion of foreigners in Switzerland. All three indicators assess exclusionary attitudes towards immigrants. While the first two indicators relate to setting criteria for immigrants who attempt to enter the country, the third one relates to the desired immigrant/host population ratio of residents.

Our main model tests the hypothesis that chronic disease threat (operationalized with the germ aversion scale; Duncan, Schaller, \& Park, 2009) predicts contextual disease threat (operationalized with appraisal of avian influenza threat), which in turn will increase exclusionary immigration attitudes. Chronic disease threat should also enhance support for exclusion of immigrants indirectly through BDW and SDO (see Hodson \& Costello, 2007). Moreover, contextual avian influenza threat should be positively related to BDW, since an avian influenza pandemic should lead to a representation of society which implies a clear dividing line between safe and healthy individuals on the one hand and dangerous and unhealthy individuals on the other. We expect similar mediational processes to underlie all three exclusionary immigration attitudes. However, as the disease threats are conceptually related to health immigration criteria, these links should be stronger than for the assimilationist immigration criteria and for the desired immigrant/host population ratio. We also test an alternative model which conceptualizes BDW as an indicator of general anxiety which then leads to exclusionary immigration attitudes (see Schaller, Park, \& Faulkner, 2003).

\section{METHOD}

\section{Participants and procedure}

Five hundred and twenty students from four French-speaking Swiss universities participated in the survey during lectures. One hundred eight participants $(21 \%)$ were not Swiss and were excluded from further analyses (this percentage roughly corresponds to the proportion of foreigners in Switzerland). This resulted in a final sample of 412 participants (39\% men and 61\% women; mean age 21 years, $S D=3.59$ years). Participation was voluntary, and no compensation was offered. After completing the questionnaire, each participant had the option to discuss the aims of the study with questionnaire administrators. After data collection was completed, participants were sent a written debriefing describing preliminary results. 


\section{Measures}

Chronic disease threat. Chronic disease threat was assessed with three items tapping germ aversion (i.e. 'It really bothers me when people sneeze without covering their mouths', 'I don't like to write with a pencil someone else has obviously chewed on', 'I prefer to wash my hands pretty soon after shaking someone's hand'; Duncan et al., 2009; $\alpha=.64)$.

Contextual disease threat. Four items measured perceived (contextual) avian influenza threat (i.e. 'To what extent are you worried about avian influenza?', 'How often do you think about avian influenza', 'How often do you talk about avian influenza with other people', 'How much attention do you pay to information concerning avian influenza in the media'; $\alpha=.79$ ).

Ideological belief systems. Ideological orientations were assessed with a six-item SDO scale (drawn from Pratto, Sidanius, Stallworth, \& Malle, 1994; $\alpha=.82$ ) and a six-item BDW scale (drawn from Altemeyer, 1988; $\alpha=.77$ ). Short versions of the original scales were employed to keep the questionnaire brief.

Exclusionary immigration attitudes. To measure support for immigration criteria, participants were asked how important seven characteristics were in deciding whether someone born, brought up and living outside the country should be allowed to come and live in Switzerland. Five items tapped assimilationist immigration criteria (speaking the country's language, working skills, Christian origins, adopting the Swiss way of life, being wealthy; Green, 2009; $\alpha=.71)$. Two items tapped health-related immigration criteria (being in good health, not having contagious diseases; $\alpha=.72$ ). Participants were also asked to estimate the actual percentage of foreigners in Switzerland and then the ideal percentage of foreigners. A reduction-of-proportion-of-foreigners-score was created by subtracting the ideal percentage of foreigners from the perceived actual percentage. Positive scores thus indicate a desire to reduce the number of immigrants in Switzerland, whereas negative scores indicate a desire to increase the number of foreigners. Eighty-one respondents (20\%) failed to indicate the ideal percentage of foreigners in Switzerland. Among the remaining 331 respondents, scores of 16 outliers (i.e. seven estimations of actual percentages and nine estimations of ideal percentages with standardized scores in excess of 3.29) were replaced by assigning them the next most extreme score in the distribution (Tabachnick \& Fidell, 2001).

Besides the reduction-of-proportion-of-foreigners-score, all items were assessed with Likert scales ranging from 1 to 5 where higher scores indicated stronger agreement with the question. Gender, age and university were controlled for in preliminary regression analyses. These variables did not influence the hypothesized result patterns and were thus excluded from the presented models. ${ }^{1}$

\section{RESULTS}

\section{Correlations}

Bivariate correlations between all the variables are displayed in Table 1. As expected, chronic disease threat (germ aversion) was positively, though moderately, related to avian

\footnotetext{
${ }^{1}$ Inclusion of control variables revealed only one effect. Women were more willing than men to reduce the percentage of foreigners in Switzerland, $B=-3.94 S E=1.63, p<.05$. This effect explained $1 \%$ of the variance. 


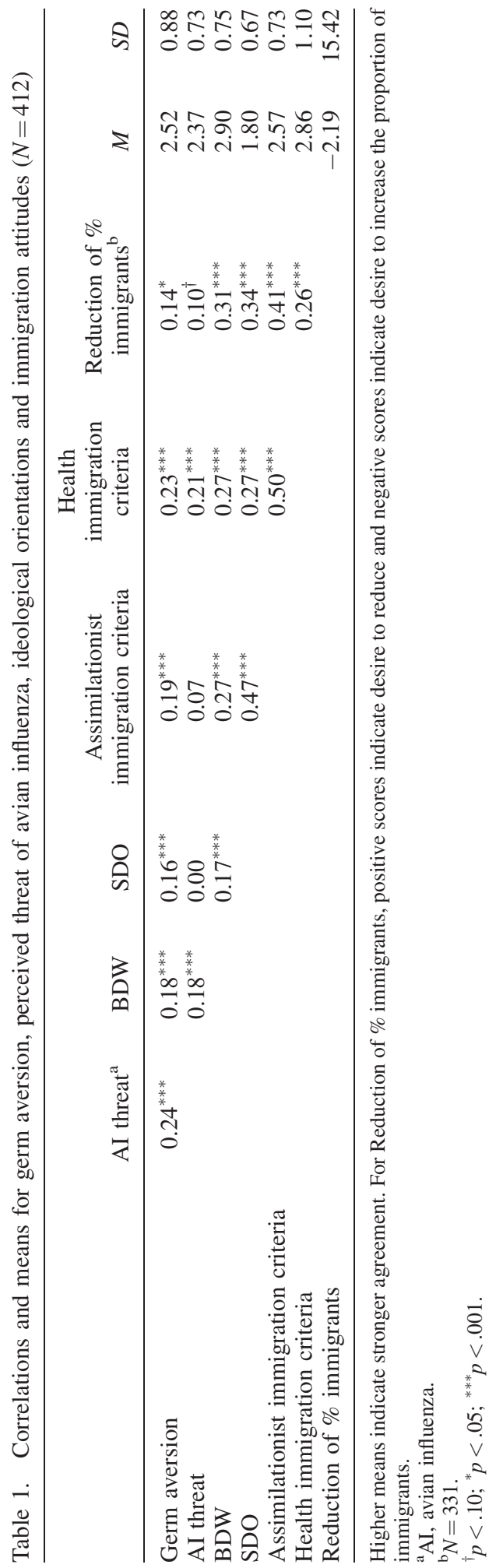


influenza threat, to the ideological orientations (SDO, BDW) and to the three exclusionary immigration attitudes (support for assimilationist and health immigration criteria and the desire to reduce the proportion of immigrants). Contextual disease threat (perceived avian influenza threat) was positively related to BDW and to support for health immigration criteria. Ideological orientations were positively related to all three anti-immigration attitudes. Given the conceptual distinction between the indicators discussed above, assimilationist immigration criteria and health immigration criteria scores were analysed separately despite their correlation $(r=.50)$.

\section{Disease threat model}

Next, three multiple mediation structural equation models (Preacher \& Hayes, 2008) were tested with Mplus 5.1 to investigate whether chronic germ aversion predicted exclusionary immigration attitudes indirectly through ideological orientations (SDO, BDW) and avian influenza threat. After presenting the findings of our disease threat model, we introduce and test an alternative model that places both germ aversion and BDW as antecedents of avian influenza threat and SDO which, in turn, predict exclusionary immigration attitudes. Finally, we compare the original and the alternative models.

Since the constructs involve multiple items, latent variables were employed to enable modelling of measurement error. ${ }^{2}$ Because the structural model is the main focus of this study and in order to simplify presentation of results, only the relationships between the latent variables are shown in the figures. The covariances among the error terms for the ideological orientations were significant $(\psi=.30, p<.001)$, suggesting a positive relationship between BDW and SDO, but this relation is also excluded from Figure 1.



Figure 1. Support for assimilationist immigration criteria, support for health immigration criteria and desire to reduce proportion of foreigners as a function of germ aversion, avian influenza threat, SDO and BDW (standardized coefficients). Note: Results for support for assimilationist immigration criteria, support for health immigration criteria and desire to reduce proportion of foreigners, respectively, are separated by slashes. ${ }^{*} p<.05 ;{ }^{* *} p<.01 ;{ }^{* * *} p<.001$.

\footnotetext{
${ }^{2}$ Following the modification indexes, three error terms of BDW items and two error terms of SDO items were allowed to correlate within latent constructs.
} 
The first model examines the role of ideological orientations and perceived avian influenza threat as mediators in the relationship between germ aversion and support for assimilationist immigration criteria. As Figure 1 shows, germ aversion predicted all the hypothesized mediators, that is $\operatorname{BDW}(\beta=.23)$, $\operatorname{SDO}(\beta=.24)$ and avian influenza threat $(\beta=.32)$. As expected, avian influenza threat was related to $\operatorname{BDW}(\beta=.19)$. Of the hypothesized mediators, $\operatorname{SDO}(\beta=.56)$ and $\operatorname{BDW}(\beta=.22)$ predicted support for assimilationist immigration criteria, but unexpectedly avian influenza threat did not. Germ aversion was not directly related to support of assimilationist immigration criteria. Consistent with our expectations, however, the relationship between germ aversion and support for assimilationist immigration criteria was mediated by SDO (standardized indirect effect of germ aversion on support for assimilationist immigration criteria $=0.13$, $S E=0.04,95 \%$ CI $0.05,0.21$ ) and BDW (standardized indirect effect of germ aversion on support for assimilationist immigration criteria $=0.05, S E=0.02,95 \%$ CI $0.01,0.10){ }^{3}$ The results further show an indirect effect of avian influenza threat on support for assimilationist immigration criteria via BDW (standardized indirect effect 0.04, $S E=0.02$, $95 \%$ CI 0.01, 0.08). The model had good overall fit, $\chi^{2}(236, N=412)=379.92, p<.001$, $\mathrm{CFI}=0.95, \mathrm{RMSEA}=0.038(90 \%$ CI 0.031, 0.045), $\mathrm{SRMR}=0.05, \mathrm{AIC}=25480$.

Turning to our second model, as predicted, we found that perceived avian influenza threat $(\beta=.14)$ as well as both $\operatorname{BDW}(\beta=.26)$ and $\operatorname{SDO}(\beta=.22)$ were significant predictors of support for health immigration criteria. Germ aversion was directly related to support for health immigration criteria $(\gamma=.16)$. In line with our expectations, the relationship between germ aversion and support for health immigration criteria was partially accounted for by indirect effects of SDO (standardized indirect effect $=0.05$, $S E=0.02,95 \%$ CI $0.01,0.10$ ), and BDW (standardized indirect effect $=0.06, S E=0.03$, $95 \%$ CI $0.01,0.11$ ). Moreover, an indirect effect between avian influenza threat and support for health criteria via BDW was revealed (standardized indirect effect $=0.05, S E=0.02$, 95\% CI 0.004, 0.10). Model fit was good, $\chi^{2}(174, N=412)=262.95, p<.001$, $\mathrm{CFI}=0.97, \mathrm{RMSEA}=0.035$, (90\% CI 0.026, 0.044), $\mathrm{SRMR}=0.048, \mathrm{AIC}=22445$.

The final model investigated the desire to reduce the proportion of foreigners in the country. A similar pattern of results as for support for assimilationist immigration criteria was found. $\operatorname{SDO}(\beta=.26)$ and $\operatorname{BDW}(\beta=.29)$ predicted the desire to reduce the proportion of foreigners in Switzerland, while avian influenza threat did not. The direct relationship between germ aversion and the desire to reduce the number of foreigners no longer reached significance. An indirect relationship between germ aversion and the desire to reduce the percentage of foreigners was found mediated by SDO (standardized indirect effect $=0.06$, $S E=0.02,95 \%$ CI $0.02,0.11$ ) and BDW (standardized indirect effect $=0.07, S E=0.03$, $95 \%$ CI 0.01, 0.12). Moreover, the link between avian influenza threat and desire to reduce the number of immigrants passed through BDW (standardized indirect effect $=0.06$, $S E=0.02,95 \%$ CI $0.01,0.10)$. Model fit was good, $\chi^{2}(156, N=331)=256.10, p<.001$, $\mathrm{CFI}=0.96$, RMSEA $=0.04$, (90\% CI 0.03, 0.05), $\mathrm{SRMR}=0.05, \mathrm{AIC}=22679$.

These findings indicate that chronic germ aversion exerted both a direct and indirect impact on exclusionary immigration attitudes. In order to verify that the structural component affected model fits, the significant paths were one by one constrained to zero in the three models (Kline, 2005). Indeed, the structural component improved the three model

\footnotetext{
${ }^{3}$ To obtain accurate confidence intervals, we computed indirect effects from standardized regression weights with 2000 bootstrap resamples (Preacher \& Hayes, 2008). Note that indirect effect analyses are essentially equivalent to Sobel tests.
} 
fits over and above the measurement components $\left(\Delta \chi^{2}\right.$ ranged between 10.03 and 75.95 , all $p s<.01$ for assimilationist immigration criteria; between 4.77 and 27.32, all $p s<.05$ for health immigration criteria; between 9.87 and 27.19, all $p \mathrm{~s}<.01$ for desire to reduce proportion of foreigners).

\section{An alternative model}

Our disease threat model conceptualized ideological beliefs as triggered by germ aversion. This assumption determined the causal order of the model in which germ aversion preceded ideological beliefs. Germ aversion was also assumed to precede avian influenza threat. However, an alternative, evolutionary rationale is possible: During evolutionary history physical danger came both from disease and from threatening individuals (Diamond, 1997; Schaller et al., 2003). Consequently, a more general form of anxiety gave rise to a vigilant avoidance of potentially injurious intergroup encounters (Schaller et al., 2003). In this view, BDW is a measure of interpersonal fear while germ aversion is a measure of disease threat. Both share the function of assessing physical danger. The response to this perceived danger is twofold: Individuals are more vigilant towards new diseases such as avian influenza and they support a hierarchical organization of their group where supposedly healthy dominants have control over supposedly unhealthy subordinates. These two responses then translate into avoidance of potentially threatening intergroup contact. Consequently, this alternative model places both germ aversion and BDW as antecedents of avian influenza threat and SDO. SDO and avian influenza threat then translate into exclusionary immigration attitudes. We refer to this model as the generalized intergroup vigilance model.

As our original disease threat model and the alternative generalized intergroup vigilance model are not nested, Akaike Information Criteria (AIC) are compared: The model to be preferred has the lowest AIC value (see Kline, 2005 on comparing non-hierarchical models). The results show that the generalized intergroup vigilance model yielded a slightly worse fit compared to the predicted model for all three immigration attitudes: $\chi^{2}(237, N=412)=393.80, p<.001, \mathrm{CFI}=0.95, \mathrm{RMSEA}=0.04(90 \%$ CI $0.03,0.05)$, $\mathrm{SRMR}=0.05, \mathrm{AIC}=25493$ for assimilationist criteria; $\chi^{2}(175, N=412)=284.40$, $p<.001, \mathrm{CFI}=0.96, \mathrm{RMSEA}=0.04(90 \%$ CI 0.03, 0.05), $\mathrm{SRMR}=0.05, \mathrm{AIC}=22464$ for health criteria; $\chi^{2}(157, N=331)=275.63, p<.001, \mathrm{CFI}=0.95, \mathrm{RMSEA}=0.04(90 \%$ CI $0.03,0.05), S R M R=0.05, \mathrm{AIC}=22696$, for desire to reduce proportion of foreigners. One should note, however, that since the structural components of the model had less impact on the model fits than the measurement component, variation in model fits was modest. The preference over models should thus be based on theoretical arguments.

\section{DISCUSSION}

The chief aim of this research was to examine how perceived disease threat translates into exclusionary immigration attitudes. While the link between disease threat and prejudice has been previously studied, this study is, to our knowledge, the first to investigate the mediating mechanisms underlying it. Unlike previous research, we also investigated simultaneously the impact of chronic disease threat (germ aversion) and contextual reallife disease threat, that is, avian influenza. Building on evolutionary theory and social representations theory, we tested a model where the impact of germ aversion on 
anti-immigration stances was partially mediated by contextual disease threat and two ideological beliefs systems: A belief that group-based hierarchy should be maintained (SDO) and the belief that society is a dangerous place (BDW). Supporting our model, germ aversion was directly or indirectly (through SDO and BDW) related to support of all three exclusionary immigration attitudes. However, perceived threat of avian influenza pandemic was only directly related to support for strict health-based immigration criteria.

Let us first discuss the finding that perceived avian influenza threat only led to domainspecific (i.e. health-related) prejudicial reactions. Two reasons can explain the absence of a generalized effect of avian influenza threat. First, human-to-human transmission was highly unlikely at the time of the study. Though the origin of the outbreak was in Asia, avian influenza was not associated with any particular outgroups, Asian or other. This sets avian influenza apart from infectious diseases which have been associated with particular groups such as SARS with Asians or HIV with homosexual men (e.g. Des Jarlais, Galea, Tracy, Tross, \& Vlahov, 2006). In such instances, prejudice towards these groups is more likely to emerge (Jiang et al., 2009; Person et al., 2004). In our study, it thus appears that perceived avian influenza threat was not strong enough to translate into generalized prejudice. Second, the spread of avian flu was mainly associated to migrating birds, and thus beyond the control of any particular outgroup. The fact that avian influenza threat did not translate (directly) into prejudice thus seems to reflect the fact that in this case stigmatization of infected individuals could not be justified with a lack of control and responsibility to avoid the disease (e.g. Mak, Mo, Cheung, Woo, Cheung, \& Lee, 2006; see Leppin \& Aro, 2009 for an overview on SARS and avian influenza).

Based on the argument that fear of both interpersonal harm and disease leads to disease vigilance and a desire for a hierarchical society, we evaluated an alternative generalized intergroup vigilance model that positioned BDW and germ aversion prior to SDO and to contextual avian influenza threat in the causal chain. This model had slightly inferior fits for the three measures compared to our original disease threat model. Empirically, it is therefore difficult to decide which model is more appropriate. In our view, however, disease threat evokes normative representations of how to regulate social order in face of a threatening situation. BDW stands for a model of society which is based on a clear dividing line between healthy and trustworthy individuals on the one hand, and unhealthy and thus potentially dangerous individuals on the other. SDO, in turn, advocates a society where dominant groups rule over subordinate groups, a strategy which was to some extent perceived to be effective in order to handle pandemic threat. Both belief systems then lead to a desire to avoid potentially harmful intergroup contact and thus to negative intergroup attitudes. Thus, the main difference between the models lies in the interpretation of BDW: In the disease threat model, BDW is an ideological and normative belief about the functioning of society shared by its members. In the intergroup vigilance model, BDW assesses a chronic individual-level fear of interpersonal harm and aggression. In line with the social representational arguments underlying this research, we favour the former of these two views.

\section{Evolutionary and social representations approaches: Unlikely bedfellows?}

Our research was based on a conceptual framework integrating evolutionary and social representational approaches. The presented model was not designed to compare the predictive power or validity of these two theories, but to build on the common ground they share in explaining demarcation of national group boundaries by exclusion of potentially disease-carrying immigrants. While an in-depth discussion of the epistemological and 
meta-theoretical differences is beyond the scope of this paper (see Tooby \& Cosmides, 1992; Wagner \& Hayes, 2005; Wagner \& Wagner, 2003), some commonalities of these two approaches deserve to be outlined.

First, both approaches converge in a view of inherent sociality and interdependence of human behaviour where communication plays a central role of coordination of human activities. From an evolutionary perspective, communication is essential for effective coordination in interdependent and cooperative groups when facing environmental challenges such as disease (Brewer, 1999). From a social representational view, communication fulfils a function of collective meaning making through which individuals collectively cope with the experience of danger and threat disseminated by mass media (Wagner et al., 2002). Therefore, evolutionary and social representations approaches complement each other. While an evolutionary perspective allows understanding the adaptive reactions to disease threat derived from our ancestral societies (see Curtis, 2007), the social representational approach highlights the normative and ideological belief systems through which evolved mechanisms translate into social and political attitudes in contemporary society (Clémence, 2001; Doise \& Staerklé, 2002; Staerklé, 2009). The model presented in this paper demonstrated that cultural constructions-normative belief systems promoting differentiation and hierarchy_function as (partial) mediators between evolved mechanisms of germ aversion and exclusionary immigration attitudes.

Both approaches also highlight the role of negative affect in explaining the link between disease threat and prejudice. Negative affect was not assessed in this research but has been found to play an important role. In the social representational approach, disgust, for example, can be elicited when individuals encounter outgroup members who promote values contrasting those of the ingroup or who potentially carry contagious diseases (Joffe $\&$ Staerklé, 2007). Here, disgust originates from the earliest months of life, but is cultivated by messages the society conveys to an individual (Joffe, 1999; see also Rozin et al., 2000). From an evolutionary intergroup perspective, in turn, this affect is shaped by natural selection to address survival-related problems and is associated with potentially harmful and contagious outgroups (Cottrell \& Neuberg, 2005).

Both approaches rely on anthropological evidence in theory building. Evolutionary-informed research employs anthropological and ethnographic data to examine the universality of a phenomenon across cultures. Such research allows distinguishing disease protective practices that are evolutionary adaptations from context-specific and culturally-instantiated manifestations (Norenzayan, Schaller, \& Heine, 2006; van Vugt \& Schaller, 2008). The social representational approach concerned with risk perception (Joffe, 2003) refers to the protective role of taboo in primitive societies (Douglas, 1992) in order to investigate collective coping with emerging threatening diseases in modern society. In her research on representations of madness, Jodelet (1991) used such evidence to analyse interactions of community members with mentally ill members of their community. Thus, while evolutionary-informed approaches assume some degree of universality in psychological processes underlying threat-based reactions and aim to discover human universals across cultures, a social representational approach highlights the cultural specificity of the social construction of threat.

\section{Limitations and conclusion}

Shortcomings of our study need to be acknowledged. First, due to the cross-sectional and correlational nature of our data, we are of course not in a position to advance unequivocal causal claims about the impact of disease threat on hostile immigration attitudes. Nevertheless, in light of both the evolutionary and the social representations perspectives, 
such causal links between normative and ideological belief systems and attitudes towards outgroups seem plausible.

Also, data gathered with a single version of a questionnaire can be plagued by context effects (e.g. Krosnick, 1999; Tourangeau, Rips, \& Rasinski, 2000). One could for example argue that germ aversion items prime negative responses on immigration attitudes. However, the items employed in the current study were part of a longer survey questionnaire. Since a considerable number of other items (which are not related to this research) were included between the items used for our analysis, potential priming effects should not be a serious issue. Moreover, given the existing experimental evidence of the link between disease threat and prejudice (Faulkner et al., 2004) and the recent overview of Duncan et al. (2009) demonstrating across 22 studies the discriminant and predictive validity of germ aversion for prejudiced attitudes, we are confident that our findings are not merely due to order effects.

Another issue concerns the difficulty to discriminate between effects of exposure to threatinducing messages (e.g. learning about avian influenza in the media) and pre-existing sensitivities (i.e. germ aversion). Our data cannot solve this problem, and experimental studies are needed to overcome this limitation inherent in our cross-sectional study. Another option would be to directly study the actual collective elaboration of the avian influenza pandemic in public discourse and media. The contextual threat measure used in this research assessed the frequency of discussing avian flu with others and attention given to media coverage; it is thus only a proxy of such collective elaboration (see Joffe \& Lee, 2004).

The relatively modest links between germ aversion and exclusionary immigration attitudes could also be seen as a cause for concern. The relationships were nevertheless consistent across the three measures and correspond to the strength revealed in prior research on attitudes towards unspecified immigrant groups (Faulkner et al., 2004; Navarette \& Fessler, 2006).

Finally, as in most research in social psychology, student samples employed in this study may impede broad generalization to the general public as the range of prejudiced attitudes may be restricted (Henry, 2008). Students compared to the general adult population have less crystallized attitudes (Sears, 1986) and liberal university climates usually cultivate tolerant worldviews or at least raise students' awareness of prevailing anti-discrimination norms. By testing our model with a student sample, we thus submitted it to a stricter test than with a general population sample. Yet, recent studies with a general adult population reveal similar standard deviations in measures and replicate the correlation patterns found in this study (Bangerter, Green, \& Clémence, 2009). We are therefore confident that the relationships revealed in this study have sufficient external validity.

Notwithstanding these limitations, we believe that this research contributes to a better understanding of the social psychological processes triggered by disease threat. The fact that fear of disease relates to negative perceptions and avoidance of outgroups should be cause for concern, since such processes can easily amplify the adverse social consequences of pandemic disease. The current research shed some light on the normative processes underlying the pernicious relationship between perceived disease threat and prejudice and thus on the collective consolidation of the boundary between 'us' and 'them'.

\section{ACKNOWLEDGEMENTS}

Portions of this paper were presented at the 15th General Meeting of the European Association of Experimental Social Psychology, 10-14 June 2008, Opatija, Croatia and at 
the 32nd Annual Meeting of the International Society of Political Psychology, 14-17 July 2009, Dublin, Ireland. The authors are thankful to Ingrid Gilles for insightful comments on a previous draft and John Antonakis for methodological counsel. The research was supported by the Swiss National Science Foundation (100014_122366).

\section{REFERENCES}

Allport, G. W. (1954). The nature of prejudice. Cambridge, MA: Addison-Wesley.

Altemeyer, B. (1988). Enemies of freedom. San Francisco: Jossey-Bass.

Augoustinos, M., Walker, I., \& Donaghue, N. (2006). Social cognition: An integrated introduction (2nd ed.), London: Sage.

Bangerter, A., Green, E. G. T., \& Clémence, A. (2009). Dynamic public perceptions of emerging infectious diseases. Unpublished raw data.

Bar-Tal, D. (1990). Group beliefs: A conception for analyzing group structure, processes and behavior. New York: Springer-Verlag.

Brewer, M. B. (1999). The psychology of prejudice: Ingroup love or outgroup hate. Journal of Social Issues, 55, 429-444.

Clémence, A. (2001). Social positioning and social representations. In K. Deaux, \& G. Philogène (Eds.), Representations of the social (pp. 83-95). Oxford: Blackwell Publishers.

Cottrell, C. A., \& Neuberg, S. L. (2005). Different emotional reactions to different groups: A sociofunctional threat-based approach to "prejudice". Journal of Personality and Social Psychology, 88, 770-789.

Curtis, V. A. (2007). Dirt, disgust and disease: A natural history of hygiene. Journal of Epidemiology and Community Health, 61, 660-664.

de Zwart, O., Veldhuijzen, I. K., Elam, G., Aro, A. R., Abraham, T., \& Bishop, G. D., et al. (2007). Avian influenza risk perception, Europe and Asia. Emerging Infectious Diseases, 13, 290-293.

Des Jarlais, D. C., Galea, S., Tracy, M., Tross, S., \& Vlahov, D. (2006). Stigmatization of newly emerging infectious diseases: AIDS and SARS. American Journal of Public Health, 96, 561-567.

Diamond, J. (1997). Guns, germs, and steel. New York: Norton.

Doise, W. (1990). Les représentations sociales [Social representations]. In C. Bonnet, R. Ghiglione, \& T. F. Richard (Eds.), Traité de Psychologie Cognitive (Vol. 3, pp. 111-174). Paris: Dunod.

Doise, W., \& Staerklé, C. (2002). From social to political psychology: The societal approach. In K. R. Monroe (Ed.), Political psychology (pp. 151-171). Mahwah, NJ: Lawrence Erlbaum.

Doty, R. M., Peterson, B. E., \& Winter, D. (1991). Threat and authoritarianism in the United States, 1978-1987. Journal of Personality and Social Psychology, 61, 629-640.

Douglas, M. (1992). Risk and blame. Essays in cultural theory. London: Routledge.

Duckitt, J. (2001). A dual process cognitive-motivational theory of ideology and prejudice. In M. P. Zanna (Ed.), Advances in experimental social psychology (Vol. 33, pp. 41-113). San Diego: Academic Press.

Dudo, A. D., Dahlstrom, M. F., \& Brossard, D. (2007). Reporting a potential pandemic. A risk-related assessment of avian influenza coverage in U.S. newspapers. Science Communication, 28, 429-454.

Duncan, L. A., Schaller, M., \& Park, J. H. (2009). Perceived vulnerability to disease: Development and validation of a 15-item self-report instrument. Personality and Individual Differences, 37, 541-546.

Esses, V. M., Jackson, L. M., \& Armstrong, T. L. (1998). Intergroup competition and attitudes toward immigrants and immigration: An instrumental model of group conflict. Journal of Social Issues, 54, 699-724.

Faulkner, J., Schaller, M., Park, J. H., \& Duncan, L. A. (2004). Evolved disease-avoidance mechanisms and contemporary xenophobic attitudes. Group Processes \& Intergroup Relations, 7, 333-353.

Green, E. G. T. (2007). Guarding the gates of Europe: A typological analysis of immigration attitudes in 21 European countries. International Journal of Psychology, 42, 365-379.

Green, E. G. T. (2009). Who can enter? A multilevel analysis on public support for immigration criteria across 20 European countries. Group Processes \& Intergroup Relations, 12, 41-60. 
Guimond, S., Dambrun, M., Michinov, N., \& Duarte, S. (2003). Does social dominance generate prejudice? Integrating individual and contextual determinants of intergroup cognitions. Journal of Personality and Social Psychology, 84, 697-721.

Haselton, M. G., \& Nettle, D. (2006). The paranoid optimist: An integrative evolutionary model of cognitive biases. Personality and Social Psychology Review, 10, 47-66.

Henry, P. J. (2008). College sophomores in the laboratory redux: Influences of a narrow data base on social psychology's view of the nature of prejudice. Psychological Inquiry, 19, 49-71.

Ho, S. S., Brossard, D., \& Scheufele, D. A. (2007). The polls trends: Public reactions to global health threats and infectious diseases. Public Opinion Quarterly, 71, 671-692.

Hodson, G., \& Costello, K. (2007). Interpersonal disgust, ideological orientations, and dehumanization as predictors of intergroup attitudes. Psychological Science, 18, 691-698.

Jiang, X., Elam, G., Yuen, C., Voeten, H., Zwart, O., \& Veldhuijzen, I., et al. (2009). The perceived threat of SARS and its impact on precautionary actions and adverse consequences: A qualitative study among Chinese communities in the United Kingdom and the Netherlands. International Journal of Behavioral Medicine, 16, 58-67.

Jodelet, D. (1991). Madness and social representations. London: Harvester Wheatsheaf.

Jodelet, D. (2005). Formes et figures d'alterité [Forms and figures of otherness]. In M. SanchezMazas, \& L. Licata (Eds.), L'Autre. Regards psychosociaux (pp. 23-47). Grenoble, France: Presses Universitaires de Grenoble.

Joffe, H. (1999). Risk and the "other". Cambridge: Cambridge University Press.

Joffe, H. (2003). Risk: From perception to social representation. British Journal of Social Psychology, $42,55-73$.

Joffe, H., \& Haarhoff, G. (2002). Representations of far-flung illnesses: The case of Ebola in Britain. Social Science and Medicine, 54, 955-969.

Joffe, H., \& Lee, N. Y. L. (2004). Social representation of a food risk: The Hong Kong avian bird flu epidemic. Journal of Health Psychology, 9, 517-533.

Joffe, H., \& Staerklé, C. (2007). The centrality of the self-control ethos in Western aspersions regarding outgroups: A social representational analysis of common stereotype content. Culture and Psychology, 13, 395-418.

Jost, J. T., \& Major, B. (2001). The psychology of legitimacy. Cambridge: Cambridge University Press.

Kline, R. (2005). Principles and practice of structural equation modeling (2nd ed.), New York: Guilford press.

Krings, F., Green, E. G. T., Bangerter, A., Staerklé, C., Bornand, T., \& Clémence, A., et al. (2009). Preventing contagion with avian influenza: Attitudes toward foreigners moderate the relation between perceived threat and outgroup avoidance beliefs. Manuscript submitted for publication.

Krosnick, J. A. (1999). Survey research. Annual Review of Psychology, 50, 537-567.

Kurzban, R., \& Leary, M. R. (2001). Evolutionary origins of stigmatization: The functions of social exclusion. Psychological Bulletin, 127, 187-208.

Leppin, A., \& Aro, A. R. (2009). Risk perceptions related to SARS and Avian Influenza: Theoretical foundations of current empirical research. International Journal of Behavioral Medicine, 16, 7-29.

Mak, W. W. S., Mo, P. K. H., Cheung, R. Y. M., Woo, J., Cheung, F. M., \& Lee, D. (2006). Comparative stigma of HIV/AIDS, SARS, and tuberculosis in Hong Kong. Social Science \& Medicine, 63, 1912-1922 .

Markel, H., \& Stern, A. M. (2002). The foreignness of germs: The persistent association of immigrants and disease in American society. The Milbank Quarterly, 80, 757-788.

Navarette, C. D., \& Fessler, D. M. T. (2006). Disease avoidance and ethnocentrism: The effects of disease vulnerability and disgust sensitivity on intergroup attitudes. Evolution and Human Behavior, 27, 270-282.

Nemeroff, C. J. (1995). Magical thinking about illness virulence: Conceptions of germs from "safe" versus "dangerous" others. Health Psychology, 14, 147-151.

Norenzayan, A., Schaller, M., \& Heine, S. J. (2006). Evolution and culture. In M. Schaller, J. A. Simpson, \& D. T. Kenrick (Eds.), Evolution and social psychology (pp. 343-366). New York: Psychology Press.

Öhman, A., \& Mineka, S. (2001). Fears, phobias, and preparedness: Toward an evolved module of fear and fear learning. Psychological Review, 108, 483-522.

Osterholm, T. (2005). Preparing for the next pandemic. Foreign Affairs, 84, 24-37. 
Park, J. H., Faulkner, J., \& Schaller, M. (2003). Evolved disease-avoidance processes and contemporary anti-social behavior: Prejudicial attitudes and avoidance of people with physical disabilities. Journal of Nonverbal behavior, 27, 65-87.

Park, J. H., Schaller, M., \& Crandall, C. S. (2007). Pathogen-avoidance mechanisms and the stigmatization of obese people. Evolution and Human Behavior, 28, 410-414.

Pehrson, S., \& Green, E. G. T. (in press). Who we are and who can join us: National identity content and entry criteria for new immigrants. Journal of Social Issues.

Person, B., Sy, F., Holton, K., Govert, B., \& Liang, A. NCID/SARS community outreach team. (2004). Fear and stigma: The epidemic within the SARS outbreak. Emerging Infectious Diseases, 10, 358-363.

Pratto, F., Sidanius, J., Stallworth, L. M., \& Malle, B. F. (1994). Social dominance orientation: A personality variable predicting social and political attitudes. Journal of Personality and Social Psychology, 67, 741-763.

Preacher, K. J., \& Hayes, A. F. (2008). Asymptotic and resampling strategies for assessing and comparing indirect effects in multiple mediator models. Behavior Research Methods, 40, 879-891.

Riek, B. M., Mania, E. W., \& Gaertner, S. L. (2006). Intergroup threat and outgroup attitudes: A metaanalytic review. Personality and Social Psychology Review, 10, 336-353.

Rozin, P., Haidt, J., \& McCauley, C. R. (2000). Digust. In M. Lewis, \& J. M. Haviland-Jones (Eds.), Handbook of emotions (2nd ed., pp. 637-653). New York: Guilford Press.

Sanchez-Mazas, M., \& Licata, L. (2008). Qui a peur de l'Autre? Emotion, pensée et mise en altérité dans l'oeuvre de Denise Jodelet. In B. Madiot, E. Lage, \& A. Arruda (Eds.), Une approche engagée en psychologie sociale: L'oeuvre de Denise Jodelet (An engaged approach to social psychology : The work of Denise Jodelet), Ramonville Saint-Agne, France: Editions érès.

Savage, R. (2007). "Disease incarnate": Biopolitical discourse and genocidal dehumanisation in the age of modernity. Journal of Historical Sociology, 20, 404-440.

Schaller, M. (2006). Parasites, behavioral defenses, and the social psychological mechanisms through which cultures are evoked. Psychological Inquiry, 17, 96-101.

Schaller, M., \& Murray, D. R. (2008). Pathogens, personality, and culture: Disease prevalence predicts worldwide variability in sociosexuality, extraversion, and openness to experience. Journal of Personality and Social Psychology, 95, 212-221.

Schaller, M., Park, J. H., \& Faulkner, J. (2003). Prehistoric dangers and contemporary prejudices. European Review of Social Psychology, 14, 105-137.

Sears, D. O. (1986). College sophomores in the laboratory: Influences of a narrow database on social psychology's view of human nature. Journal of Personality and Social Psychology, 51, 515-530.

Sherif, M. (1967). Group conflict and cooperation: Their social psychology. London: Routledge \& Kegan Paul.

Sidanius, J., \& Pratto, F. (1999). Social dominance: An intergroup theory of social hierarchy and oppression. New York: Cambridge University Press.

Sontag, S. (1989). AIDS and its metaphors. London: Allen Lane.

Staerklé, C. (2009). Policy attitudes, ideological values and social representations. Personality and Social Psychology Compass, 3, 1096-1112.

Stephan, W. G., \& Renfro, C. L. (2003). The role of threat in intergroup relations. In D. M. Mackie, \& E. R. Smith (Eds.), From prejudice to intergroup emotions. Differentiated reactions to social groups (pp. 191-207). New York: Psychology Press.

Suedfeld, P., \& Schaller, M. (2002). Authoritarianism and the Holocaust: Some cognitive and affective implications. In L. S. Newman, \& R. Erber (Eds.), What social psychology can tell us about the Holocaust? Understanding perpetrator behavior (pp. 68-90). Oxford: Oxford University Press.

Tabachnick, B. G., \& Fidell, L. S. (2001). Using multivariate statistics (4th ed.), Boston: Allyn \& Bacon.

The Economist. (20 October 2005). On a wing and a scare. Retrieved 1 September 2008, from http:// www.economist.com

Thornhill, R., Fincher, C. L., \& Aran, D. (2009). Parasites, democratization, and the liberalization of values across contemporary countries. Biological Reviews, 84, 113-131.

Tooby, J., \& Cosmides, L. (1992). The psychological foundations of culture. In J. Barkow, L. Cosmides, \& J. Tooby (Eds.), The adapted mind: Evolutionary psychology and the generation of culture (pp. 19-136). New York: Oxford University Press. 
Tourangeau, R., Rips, L. J., \& Rasinski, K. A. (2000). The psychology of survey response. New York: Cambridge University Press.

Wagner, W., \& Hayes, N. (2005). Everyday discourse and common sense: The theory of social representations. Basinstoke: Palgrave Macmillan.

Wagner, W., Kronberger, N., \& Seifert, F. (2002). Collective symbolic coping with new technology: Knowledge, images and public discourse. British Journal of Social Psychology, 41, 323-343.

Wagner, W., \& Wagner, G. P. (2003). Examining the modularity concept in evolutionary psychology: The level genes, mind, and culture. Journal of Cultural and Evolutionary Psychology, 1, 135-165. van Vugt, M., \& Schaller, M. (2008). Evolutionary approaches to group dynamics: An introduction. Group Dynamics: Theory, Research, and Practice, 12, 1-6.

WHO. (2009). Epidemic and pandemic alert and response: Avian influenza. Retrieved 4 April 2009, from http://www.who.int/csr/disease/ avian_influenza/en/ 